\title{
Cinética de degradação ruminal de silagens de Brachiaria decumbens com diferentes aditivos nitrogenados
}

\section{Ruminal degradation kinetic of Brachiaria decumbens silages with different nitrogen additives}

\author{
Odimári Pricila Pires do Prado ${ }^{*}$; Valter Harry Bumbieris Júnior ${ }^{1}$; \\ Anderson Rogério Floriano ${ }^{2}$; Paula Franciele da Silva Abreu²; \\ Ivone Yurika Mizubuti ${ }^{1}$; Edson Luis de Azambuja Ribeiro ${ }^{1}$; \\ Fernando Luiz Massaro Junior'; ${ }^{3}$ Eduardo Lucas Terra Peixoto ${ }^{3}$; \\ Leandro das Dores Ferreira da Silva ${ }^{1}$; Marco Aurélio Alves de Freitas Barbosa ${ }^{1}$
}

\section{Resumo}

Objetivou-se avaliar teores de aditivo nitrogenado Silogen ${ }^{\circledR}$ pasto sobre a degradabilidade ruminal in vitro por meio de produção de gases em silagens de Brachiaria decumbens. O aditivo nitrogenado continha cepas bacterianas (Bacillus subtilis, Lactobacillus curvatus, Lactobacillus plantarum e Pedicoccus acidilactici) e mínimo de nitrogênio de $360 \mathrm{~g} / \mathrm{kg}$. Os teores avaliados foram: 0,0; 1,0; 1,$5 ; 2,0$ e $2,5 \%$. No fracionamento, foram calculados os carboidratos totais $(\mathrm{CT})$, carboidratos não fibrosos (CNF), as frações solúvel e rapidamente degradável (A+B1), potencialmente degradável (B2) e não degradável (C). Os parâmetros cinéticos dos CF e CNF foram estimados a partir da técnica de produção de gases in vitro. Os dados foram analisados por meio de análise de variância à $5 \%$. Os teores de aditivo não influenciaram os $\mathrm{CT}$ e fração $\mathrm{A}+\mathrm{B} 1$. Os teores de aditivo nitrogenado influenciaram os CNF, frações B2 e C. A fraçao de CNF apresentou menor teor (22,0\%) com 2,0\% de aditivo. Os menores teores de aditivo nitrogenado $(0 ; 1,0$ e $1,5 \%)$ resultaram em maiores valores das frações B2 (média 40,2\%) e menores valores para a fração C (média 20,0\%). Não houve diferença para o volume de gases dos CNF (média 86,73 mL) e volume final dos gases produzidos (média 195,79 mL). Houve influência dos aditivos nitrogenados para o tempo de colonização, sendo o menor tempo de $3,89 \mathrm{~h}$ para $1,0 \%$. O volume de gases dos CF foi influenciado pelos teores de aditivos nitrogenados com maiores valores para $0 \%$ de $1,0 \%$, sendo 114,74 e $115,09 \mathrm{~mL}$, respectivamente. As taxas de degradação dos CFN e CF também foram influenciadas pelos teores de aditivos nitrogenados, onde apresentou-se maiores taxas para os níveis de 2,0 e 2,5\%. Conclui-se, que os níveis menores de aditivos até $1,5 \%$ promoveram a redução da fração $\mathrm{C}$ e aumento da $\mathrm{B} 2$, e uma maior produção de volume de gases dos carboidratos fibrosos nestas silagens, demonstrando melhor valor nutricional nestas silagens.

Palavras-chave: Conservação de forragem, gramínea, uréia, valor nutricional

\begin{abstract}
This study aimed to assess levels of nitrogen additive Silogen ${ }^{\circledR}$ pasto on ruminal in vitro degradability gas production in Brachiaria decumbens silages. The nitrogen additive contained bacterial strains (Bacillus
\end{abstract}

\footnotetext{
${ }^{1}$ Profs. Drs. do Dept ${ }^{\circ}$ de Zootecnia, Universidade Estadual de Londrina, UEL, Londrina, PR. E-mail: odimari@uel.br; jrbumbieris@ uel.br; mizubuti@uel.br; elar@uel.br; leandro@uel.br; maafbarbosa@uel.br

${ }^{2}$ Discentes em Zootecnia, UEL, Londrina, PR. E-mail: andersonfloriano@zootecnista.com.br; paula_250pr@hotmail.com

${ }^{3}$ Discentes de Doutorado em Ciência Animal, UEL, Londrina, PR. E-mail: massaro@uel.br; eduzootec@hotmail.com

* Autor para correspondência
} 
subtilis, Lactobacillus curvatus, Lactobacillus plantarum and Pediococcus acidilactici) and minimum nitrogen to $360 \mathrm{~g} / \mathrm{kg}$. The levels were: $0.0 ; 1.0 ; 1.5 ; 2.0$ and $2.5 \%$. In fractionation were calculated total carbohydrates (TC), non-fiber carbohydrates (NFC), soluble and rapidly degradable (A + B1), potentially degradable (B2) and degradable (C). The kinetic parameters of FC and NFC were estimated using the technique of in vitro gas production. Data were subjected to analysis of variance at $5 \%$. The level additive did not influence the TC and fraction $\mathrm{A}+\mathrm{B} 1$. The levels of nitrogen additive influenced the NFC, fractions B2 and C. For NFC content $2.0 \%$ showed the lowest $(22.0 \%)$. The lower levels of additive nitrogen $(0,1.0$ and $1.5 \%$ ) had higher fractions of B2 (average $40.2 \%$ ) and lower values for the fraction C (average $20.0 \%$ ). There was no difference in the volume of gas CNF (average 86.73 $\mathrm{mL}$ ) and final volume of gas produced (average $195.79 \mathrm{~mL}$ ). Was no influence of nitrogen additives for the time of colonization, the lowest time of $3.89 \mathrm{~h}$ to $1.0 \%$. The volume of gas of $\mathrm{FC}$ was influenced by levels of nitrogen additives with higher values to $0 \%$ from $1.0 \%$, and 114.74 and $115.09 \mathrm{~mL}$, respectively. Degradation rates of FC and FNC were also affected by the concentrations of nitrogenous additives, which presented higher rates to the levels of 2.0 and $2.5 \%$. It follows that the lower levels of additives to $1.5 \%$ promoted the reduction of the $\mathrm{C}$ fraction and increased $\mathrm{B} 2$, and greater production of gas volume of the fiber in these silages, showing better nutritional value in these silages.

Key words: Forage conservation, grassy, nutritional value, urea

\section{Introdução}

Devido à sazonalidade de clima e índices pluviométricos ocorrido no Brasil, a produção de silagem é uma importante estratégia para o fornecimento de alimentos aos animais de produção em épocas de escassez. O princípio da ensilagem é a conservação da forragem por meio da produção de ácidos orgânicos, como o ácido lático, a partir de carboidratos solúveis, os quais tem como função reduzir o $\mathrm{pH}$ e assim inibir a ação de microrganismos indesejáveis. (SANTOS; ZANINE, 2006).

No entanto, para a produção de silagem é necessário escolher espécies forrageiras, sendo desejável aquelas que tenham grande produção de massa por unidade de área e que sejam de alta qualidade para serem fornecidas aos animais (PIMENTEL et al., 1998). Muitas são as espécies que possuem grande produção de massa verde durante os períodos de chuva, sendo uma delas o capim do gênero Brachiaria que apresenta grande potencial para a produção de silagem com teor de matéria seca ideal, porém em período de rebrota esse teor de matéria seca é menor, dificultando assim o processo de fermentação (JAYME et al., 2009).

A ensilagem de forrageiras tropicais em período de seu melhor crescimento apresenta além do excesso de umidade, alguns problemas como o alto poder tampão e baixo teor de carboidratos solúveis (EVANGELISTA et al., 2004). Todos esses fatores interferem negativamente no processo de fermentação, impedindo a rápida diminuição do $\mathrm{pH}$, consequentemente promovendo fermentações indesejáveis, e assim prejudicando o valor nutritivo da silagem de capim (MARI, 2003).

Uma alternativa para conservação da silagem, principalmente de gramíneas tropicais, é a utilização de aditivos, que melhoram a qualidade da silagem, além de promoverem menores perdas qualitativas e quantitativas do material ensilado (MORAIS et al., 2012). Entre os aditivos nitrogenados se inclui a uréia que pode aumentar o valor nutritivo da silagem, diminuir as perdas de nutrientes, sem alterar o perfil de fermentação da ensilagem (FERNANDES et al., 2009).

Um dos parâmetros mais importantes da silagem é seu valor nutricional, que pode ser determinado por meio da técnica de produção de gases in vivo ou in vitro (MAURÍCIO et al., 2003). Segundo Campos et al. (2002) a produção de gases é uma técnica que permite avaliar a degradabilidade ruminal da matéria seca, o tempo de colonização microbiana e a taxa de degradação das frações de carboidratos fibrosos e não fibrosos das forragens, por meio da curva de produção de gases obtida da 
digestão microbiana.

Esta técnica de produção de gases in vitro é muito vantajosa, pois além do baixo custo, permite estimar a qualidade nutricional dos alimentos de forma mais rápida, em grande quantidade, mantendo a uniformidade físico-quimíca do local de fermentação, além de precisar de poucos animais fistulados, não havendo a necessidade de uso de muitos animais como no método in vivo (VELÁSQUEZ et al., 2010).

Deste modo, objetivou-se avaliar o efeito da inclusão de diferentes teores de aditivos nitrogenados Silogen ${ }^{\circledR}$ pasto sobre a degradabilidade in vitro pela técnica de produção de gases de silagens de capim Brachiaria decumbens.

\section{Material e Métodos}

O experimento foi conduzido na Fazenda Escola (FAZESC) e no Laboratório de Análise de Alimentos e Nutrição Animal (LANA) da Universidade Estadual de Londrina (UEL), Londrina, Paraná, localizada a latitude de $23^{\circ} 23^{\prime} \mathrm{S}$, longitude de $51^{\circ}$ $11^{\prime} \mathrm{W}$, altitude média de 566 metros e clima do tipo Cfa subtropical segundo a classificação de Köppen (BARBOSA; TAVARES FILHO; FONSECA, 2004).

Foram avaliadas amostras de silagem de capim Brachiaria decumbens, colhida no estádio de florescimento. Para o experimento utilizouse 15 manilhas de concreto, sendo que cada silo experimental usado tinha um metro de comprimento, $400 \mathrm{~mm}$ de diâmetro, $45 \mathrm{~mm}$ de espessura de parede. Foram avaliados cinco diferentes teores do aditivo nitrogenado Silogen ${ }^{\circledR}$ pasto, contendo nitrogênio (mínimo) de $360 \mathrm{~g} / \mathrm{kg}$; Bacillus subtilis de 1,25 x $10^{8} \mathrm{ufc} / \mathrm{kg}$; Lactobacillus curvatus de 1,25 x $10^{8}$ $\mathrm{ufc} / \mathrm{kg}$; Lactobacillus plantarum de 3,75 x $10^{8} \mathrm{ufc} /$ $\mathrm{kg}$; Pedicoccus acidilactici de 6, $25 \times 10^{8} \mathrm{ufc} / \mathrm{kg}$ (Biocampo Nutrição Animal, Presidente Prudente SP), sendo os teores de 0,$0 ; 1,0 ; 1,5 ; 2,0$ e $2,5 \%$ na matéria natural, com três repetições para cada teor de aditivo nitrogenado.

Os silos foram carregados manualmente, compactados, e vedados com lona de polietileno para impedir a entrada de água no interior dos silos. O período de ensilagem foi de 55 dias. Os silos foram mantidos em local descoberto, ficando expostos as intempéries climáticas.

Após o período de ensilagem, os silos foram abertos e o material coletado. No momento da coleta, o material ensilado foi homogeneizado e as amostras colocadas em sacos plásticos bem vedados e identificados. Foram descartadas da amostragem as partes superiores e inferiores do silo. Posteriormente, as amostras foram pré-secas em estufa com circulação forçada à $55^{\circ} \mathrm{C}$, durante 72 horas. Após este processo, as amostras foram moídas em moinho tipo Willey com peneira de malha de um milímetro e armazenadas para realização das análises laboratoriais.

As amostras pré-secas foram utilizadas para determinação dos teores de matéria seca (MS), matéria orgânica $(\mathrm{MO})$, proteína bruta $(\mathrm{PB})$, matéria mineral (MM), extrato etéreo (EE), lignina (LIG), fibra em detergente ácido (FDA), fibra em detergente neutro (FDN) e fibra em detergente neutro corrigido para cinzas e proteína (FDNcp). As análises de MS, $\mathrm{MO}, \mathrm{PB}, \mathrm{MM}$, EE foram determinados conforme descritos por Mizubuti et al. (2009), e análises de LIG, FDA, FDN e FDNcp, conforme Van Soest, Robertson e Lewis (1991) e modificações citadas por Detmann, Souza e Valadares Filho (2012).

As análises de capacidade tampão (CT), nitrogênio amoniacal $\left(\mathrm{NH}_{3}\right)$ e potencial hidrogeniônico $(\mathrm{pH})$ das silagens foram determinadas conforme Playne e McDonald (1966) e Silva e Queiroz (2002).

As frações dos carboidratos totais (CHOT) foram estimadas conforme Sniffen et al. (1992). Os carboidratos totais (CHOT) foram calculados a partir da seguinte fórmula: $\mathrm{CHOT}=100-$ (\% $\mathrm{PB}+\% \mathrm{EE}+\% \mathrm{MM})$. Os carboidratos não fibrosos $(\mathrm{CNF})$ correspondem às frações $\mathrm{Ae} \mathrm{B} 1$, e foi estimada 
por $\mathrm{CNF}=100-(\% \mathrm{~PB}+\% \mathrm{FDNcp}+\% \mathrm{EE}+\% \mathrm{MM})$. A fração B2 (fibra disponível) foi resultante da subtração entre a FDNcp e a fração C. A fração C (fibra indigestível) foi estimada por meio da multiplicação do valor percentual da fração de lignina pelo fator 2,4 .

A partir da técnica de produção de gases in vitro foram estimados os parâmetros cinéticos dos carboidratos fibrosos e não fibrosos. Para isto, foram pesados $300 \mathrm{mg}$ (0,03 gramas) de amostras em frascos de vidros de $50 \mathrm{~mL}$, os quais receberam 24 mL de solução tampão de McDougal (1949), que foi previamente reduzida com $\mathrm{CO}_{2}$ e mantida em banho-maria a $39^{\circ} \mathrm{C}$ até atingir o $\mathrm{pH}$ ideal $(\mathrm{pH}$ em torno de 6,8 a 6,9). Após, foram adicionados em cada frasco $6 \mathrm{~mL}$ de inóculo provindo de um bovino cânulado no rúmen, sob aspersão de $\mathrm{CO}_{2}$. Posteriormente, os frascos foram vedados com rolha de borracha para torná-los hermeticamente fechados.

O inóculo utilizado foi obtido de um bovino macho, sem raça definida, castrado, provido de cânula ruminal, com peso vivo médio de $420 \mathrm{~kg}$, com idade aproximada de 24 meses. Foram coletados manualmente, via fístula ruminal, aproximadamente $1000 \mathrm{~mL}$ de líquido, armazenado em garrafa térmica pré-aquecida a $39^{\circ} \mathrm{C}$ de temperatura e levado imediatamente ao laboratório para a realização da técnica de produção de gases in vitro. A alimentação deste bovino foi a base de silagem de sorgo e concentrado composto por milho e farelo de soja, sendo a relação volumoso:concentrado de 80:20 e a ingestão de $1,5 \%$ do peso vivo.

Após a despressurização, fez-se a mensuração da pressão dos gases produzidos pela fermentação do substrato e acumulada nos frascos por meio de um sensor de pressão acoplado a um manômetro digital, nos tempos de 1, 2, 3, 4, 5, 6, 9, 12, 18, 24, 30, 36, 48, $60,72,84,96$ e 144 horas de fermentação. Os frasco foram armazenados em estufa (BOD) à temperatura de aproximadamente $39^{\circ} \mathrm{C}$, para a realização de leituras conforme o horário estabelecido.
Os valores de pressão expressos em Psi foram convertidos em volume (mL), conforme equação pré-estabelecida para as condições locais: Volume $(\mathrm{mL})=0,5702+3,2399 \mathrm{x}$ Pressão $+0,1074 \mathrm{x}$ Pressão $^{2}\left(R^{2}=0,99\right)$, corrigidos para uma grama de matéria seca, e descontados os valores obtidos nos frascos brancos.

Para a estimação dos parâmetros cinéticos da produção de gases, os dados foram ajustados utilizando-se o modelo logístico bicompartimental (SCHOFIELD; PITT; PELL, 1994), descrito a seguir: $\mathrm{V}=\mathrm{Vcnf} /\left(1+\exp \left(2-4^{*} \mathrm{Kcnf}^{*}(\mathrm{~T}-\mathrm{L})\right)\right)$ $+\mathrm{Vcf} /\left(1+\exp \left(2-4 * \mathrm{Kcf}^{*}(\mathrm{~T}-\mathrm{L})\right)\right)$, em que Vcnf = volume máximo de produção de gases da fração dos Carboidratos Não Fibrosos (mL); Kdcnf = taxa de degradação dos carboidratos não fibrosos $\left(\mathrm{h}^{-1}\right)$; $\mathrm{L}$ = tempo de colonização (h); Vcf = volume máximo de produção de gases da fração dos Carboidratos Fibrosos $\left(\mathrm{mL} . \mathrm{g}^{-1}\right)$; Kcf $=$ taxa de digestão para a fração dos Carboidratos Fibrosos $\left(\% \cdot \mathrm{h}^{-1}\right)$ e Vfinal= volume final de gases produzidos $(\mathrm{mL})$.

Os dados obtidos do fracionamento de carboidrato foram submetidos à análise de variância, e as médias foram comparadas pelo Teste Tukey a $5 \%$ de significância utilizando o Software estatístico R DEVELOPMENT CORE TEAM (2013).

Posteriormente, os valores dos parâmetros da cinética de degradação ruminal gerados a partir do programa estatístico R DEVELOPMENT CORE TEAM (2013), com algorítimo Gauss-Newton, foram submetidos à análise de variância, segundo um delineamento inteiramente casualizado, com cinco repetições. Foi considerado o nível de 5\% de significância.

\section{Resultados e Discussão}

Os teores crescentes do aditivo nitrogenado Silogen ${ }^{\circledR}$ pasto não influenciaram $(\mathrm{P}>0,05)$ os teores de carboidratos totais (média de 82,94\%; Tabela 1). Provavelmente, os baixos teores de proteína bruta e extrato etéreo (Tabela 1) das silagens, não 
interferiram sobre os valores de carboidratos totais, pois segundo Sniffen et al. (1992), quanto maiores os teores de PB e EE, menor serão os teores de carboidratos totais encontrados.

Hernández et al. (2002) observaram valor de carboidratos totais de $84,24 \%$ para capimbraquiária, enquanto Cabral et al. (2000) avaliando alimentos volumosos, observaram valores de carboidratos totais de 81,$47 ; 83,88 ; 79,47 \%$ para capim tifton- 85 (corte de $50 \mathrm{~cm}$ ), feno coastcross e capim elefante (63 dias de idade), respectivamente. Bumbieris Junior et al. (2007) encontraram valores para os carboidratos totais variando de 81,4 a $84,2 \%$ para silagens de grama estrela roxa ( Cynodon Nlenfuensis Vanderyst) contendo diferentes aditivos.

Os teores de carboidratos não fibrosos (CNF) foram influenciados $(\mathrm{P}<0,05$, Tabela 1) pelo teores de aditivo nitrogenado Silogen ${ }^{\circledR}$ Pasto, sendo que o teor de 2,0\% de aditivo nitrogenado apresentou o menor valor (22,0\%). De acordo com Balsalobre et al. (2003) a variação no teor dos carboidratos fibrosos afeta diretamente na disponibilidade de energia para os animais ruminantes, pois o avanço da idade das gramíneas forrageiras leva a aumento nos constituintes da parede celular, reduzindo, assim, os teores de carboidratos não fibrosos e, consequentemente o fornecimento de energia de rápida e média degradação para os microrganismos presentes no rúmen.

Tabela 1. Fracionamento dos carboidratos e composição bromatológica das silagens de capim Brachiaria decumbens Stapf com diferentes teores do aditivo Silogen ${ }^{\circledR}$ pasto

\begin{tabular}{|c|c|c|c|c|c|c|c|}
\hline & \multicolumn{5}{|c|}{ Teores de aditivo nitrogenado Silogen ${ }^{\circledR}$ pasto ( $\%$ da MN) } & \multirow[t]{2}{*}{$\mathrm{P}$} & \multirow[t]{2}{*}{$\mathrm{CV}$} \\
\hline & 0,0 & 1,0 & 1,5 & 2,0 & 2,5 & & \\
\hline CHOT (\% MS) & 83,2 & 82,8 & 82,8 & 83,1 & 82,8 & 0,9987 & 2,67 \\
\hline CNF (\% MS) & $22,5 \mathrm{a}$ & $22,2 \mathrm{a}$ & $22,9 \mathrm{a}$ & $22,0 \mathrm{~b}$ & $24,4 \mathrm{a}$ & 0,0433 & 13,51 \\
\hline $\mathrm{A}+\mathrm{B} 1(\% \mathrm{MS})$ & 39,3 & 39,4 & 40,1 & 39,0 & 41,5 & 0,0664 & 8,68 \\
\hline $\begin{array}{l}\text { B2 (\% MS) } \\
\text { C (\% MS })\end{array}$ & $\begin{array}{l}40,1 \mathrm{ab} \\
20,5 \mathrm{~b}\end{array}$ & $\begin{array}{l}41,4 \mathrm{a} \\
19,1 \mathrm{~b}\end{array}$ & $\begin{array}{l}39,3 \mathrm{ab} \\
20,6 \mathrm{~b}\end{array}$ & $\begin{array}{l}37,5 \mathrm{~b} \\
23,5 \mathrm{a}\end{array}$ & $\begin{array}{l}33,6 \mathrm{c} \\
24,8 \mathrm{a}\end{array}$ & $\begin{array}{l}0,0001 \\
0,0001\end{array}$ & $\begin{array}{l}10,25 \\
8,98\end{array}$ \\
\hline Matéria seca & 29,76 & 35,77 & 26,26 & 31,55 & 31,52 & & \\
\hline $\mathrm{MM}(\% \mathrm{MS})$ & 10,6 & 10,5 & 10,7 & 10,2 & 10,6 & & \\
\hline PB (\% MS) & 4,7 & 4,8 & 5,4 & 5,6 & 5,4 & & \\
\hline EE (\% MS) & 1,5 & 1,5 & 0,8 & 0,9 & 0,8 & & \\
\hline FDN (\% MS) & 67,8 & 68,8 & 66,9 & 67,4 & 65,7 & & \\
\hline FDA $(\% \mathrm{MS})$ & 46,7 & 47,1 & 50,0 & 54,4 & 50,7 & & \\
\hline LIG $(\% \mathrm{MS})$ & 8,6 & 8,0 & 8,5 & 9,8 & 10,3 & & \\
\hline $\mathrm{pH}$ & 5,4 & 8,8 & 9,3 & 9,4 & 9,5 & & \\
\hline $\mathrm{CT}$ & 23,8 & 28,0 & 31,7 & 48,7 & 87,2 & & \\
\hline $\mathrm{N}-\mathrm{NH}_{2}$ & $\begin{array}{l}0,2 \\
0,2\end{array}$ & 0,4 & $\begin{array}{r}1,1 \\
0,9\end{array}$ & 0,8 & 1,2 & & \\
\hline
\end{tabular}

Médias seguidas por letras iguais na mesma linha não diferem pelo teste de Tukey a 5\%. MN: Matéria Natural; CHOT: Carboidratos totais; CNF: Carboidratos não fibrosos; A+B1: Fração solúvel e rapidamente degradável; B2: Fração potencialmente degradável; C: Fração não degradável; P: Probabilidade; ER: Equação de Regressão; R²: Coeficiente de determinação; CV: Coeficiente de Variação. MM: Matéria Mineral; PB: Proteína Bruta, EE: Extrato Etéreo, FDN: Fibra em Detergente Neutro, FDA: Fibra em

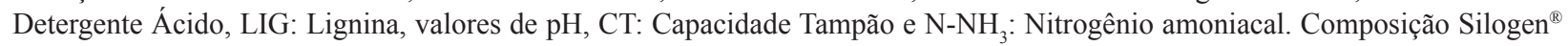
pasto: nitrogênio (mínimo) de $360 \mathrm{~g} / \mathrm{kg}$; Bacillus subtilis de $1,25 \times 10^{8} \mathrm{ufc} / \mathrm{kg}$; Lactobacillus curvatus de 1,25 x $10^{8} \mathrm{ufc} / \mathrm{kg}$; Lactobacillus plantarum de 3,75 x $10^{8} \mathrm{ufc} / \mathrm{kg}$; Pedicoccus acidilactici de $6,25 \times 10^{8} \mathrm{ufc} / \mathrm{kg}$.

Fonte: Elaboração dos autores.

Já Cabral et al (2004) ao avaliarem as frações de carboidratos de alimentos volumosos, observaram valor de $11,90 \%$ de carboidratos não fibrosos para silagem de capim-elefante.
Os diferentes teores de aditivo nitrogenado Silogen ${ }^{\circledR}$ pasto não influenciaram $(\mathrm{P}>0,05$; Tabela 1) a fração solúvel e rapidamente degradável $(\mathrm{A}+\mathrm{B} 1)$ dos carboidratos, apresentando valor 
médio de 39,86\%. Esta fração corresponde ao amido e aos carboidratos solúveis. Malafaia et al. (1998) avaliando alguns alimentos para ruminantes, observaram valores da fração $\mathrm{A}+\mathrm{B} 1$ para a silagem de milho de 21,7\% (sem aditivo), para capim tifton- 85 de 5,5\%; para Brachiaria decumbens de $11,6 \%$ e para Brachiaria brizantha valores de; e 11,3\%. Já Bumbieris Junior et al. (2007) ao avaliarem o fracionamento de carboidratos das silagens de grama estrela com diferentes aditivos contendo uréia observaram valores para a fração A+B1 entre 22,8 a 24,9\%.

Os teores crescentes do aditivo nitrogenado Silogen ${ }^{\circledR}$ pasto tiveram influência sobre a fração $\mathrm{B} 2$ dos carboidratos ( $<<0,05$, Tabela 1$)$. O teor de $1,0 \%$ de aditivo nitrogenado apresentou o maior valor $(41,4 \%)$ e o teor de $2,5 \%$ apresentou o menor valor $(33,6 \%)$. Sendo que, os teores zero e $1,5 \%$ não diferiram (40,1 e 39,3\%, respectivamente) do valor para o teor $1,0 \%$ de aditivo nitrogenado. Pode-se ainda salientar que as silagens com teores de aditivo nitrogenado zero e $1 \%$, também apresentaram maiores teores de FDN, sendo de 67,8 para a silagem contendo zero de aditivo nitrogenado e de $68,8 \%$ para a silagem contendo $1,0 \%$ de aditivo nitrogenado (Tabela 1). De acordo com Garcia et al. (2006) silagens com alto teor de FDN, apresentam maiores teores da fração B2 e estes altos teores podem afetar a eficiência da síntese microbiana e assim prejudicar o desempenho do animal, por tornar o fornecimento de energia mais lento no rúmen.

Valores entre 55,3 e 58,5\% foram observados por Bumbieris Junior et al. (2007), para silagem de grama estrela contendo diferentes aditivos com uréia, porém esses valores foram superiores ao encontrado neste trabalho. Os teores de aditivo nitrogenado Silogen ${ }^{\circledR}$ pasto influenciaram $(\mathrm{P}<0,05$, Tabela 1) a a fração $\mathrm{C}$ dos carboidratos (fração não degradável). Os teores de zero, 1,0 e 1,5\% de aditivo nitrogenado apresentaram menor fração $\mathrm{C}$ (média
20,06) em relação os teores de 2,0 e $2,5 \%$ de aditivo nitrogenado com média de 24,15\%. Observou-se que as silagens com menores teores do aditivo nitrogenado, até $1,5 \%$, apresentaram menores valores da fração não degradável $(\mathrm{C})$ em relação às demais, provavelmente, houve a ação conjunta das bactérias fibrolíticas e uréia nas proporções menores de aditivos na silagem, favorecendo as bactérias do gênero Bacillus presentes no aditivo, que produzem celulases e hemicelulases, que atuam degradando a fibra, consequentemente, melhorando a qualidade dessa silagem.

Além disso, a fração não degradável é responsável por proporcionar menor ou maior digestibilidade dos carboidratos (MALAFAIA et al., 1998). Malafaia et al. (1998) avaliando o fracionamento de carboidratos, observaram para a fração C valores de 20,2 para tifton-85; 20,8 para capim elefante; 18,8 para Braquiaria brizanta e $16,3 \%$ para $B$. decumbens. Já Bumbieris Junior et al. (2007) avaliando silagem de grama estrela com aditivo contendo uréia (10 kg/tonelada), observaram valor de $21,1 \%$ para a fração $C$.

Na Figura 1 estão representadas as curvas do volume de gases produzidos pelas silagens de Brachiaria decumbens contendo diferentes teores de aditivo nitrogenado. Notou-se, que as silagens contendo aditivos apresentaram curvas similares.

Observou-se, que o pico de produção de gases ocorreu antes das 48 horas de incubação neste experimento, demonstrando que nesse período, ocorreu maior fermentação nessas silagens, provavelmente, isso ocorreu devido à disponibilidade de substratos para os microrganismos ruminais fermentarem, assim resultando em produção de gases nessas silagens. Após, 72 horas de incubação, à produção de gases foi mais decorrente da morte celular de microrganismos ruminais, do que por meio da degradação propriamente dita das silagens. 
Figura 1. Volume de gases produzidos dos carboidratos fibrosos (CF) e carboidratos não fibrosos (CNF) da silagem de Brachiaria decumbens com diferentes teores de aditivo nitrogenado Silogen ${ }^{\circledR}$ pasto, durante as $144 \mathrm{~h}$ de incubação.

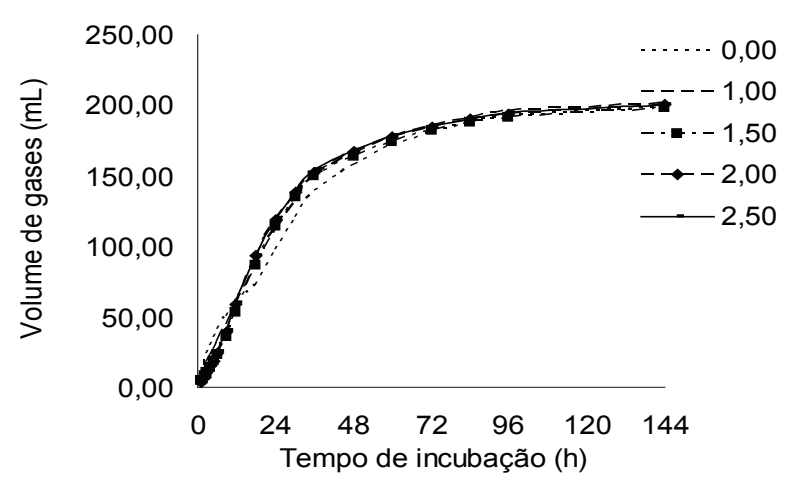

Fonte: Elaboração dos autores.

Os diferentes teores de aditivos nitrogenados Silogen ${ }^{\circledR}$ pasto não influenciaram o volume de gases produzidos pelos carboidratos não fibrosos (VCNF, $\mathrm{P}>0,05$ ), com média de 86,73 mL (Tabela 2). A silagem que apresentou numericamente o maior volume de gases dos carboidratos não fibrosos foi a que continha $2,5 \%$ de aditivo (90,81\%; Tabela 2 ). Provavelmente, isso acorreu devido a essa silagem conter os maiores teores de CNF (24,4\%; Tabela 1) e de fração A+B1 (41,5\%, P>0,05; Tabela 1), demonstrando que, quanto maior a quantidade de carboidratos não fibrosos (amido e açúcares solúveis) na silagem, maior é o volume de gases produzidos por essa fração, e, assim, consequentemente ocorreu maior fermentação na silagem que continha 2,5\% de aditivo nitrogenado (CAMPOS et al., 2000).

Sá et al. (2011) encontraram valores para o volume de gases produzidos pela fração dos carboidratos não fibrosos de 95,75; 116,8 e $68 \mathrm{~mL}$ para o capim Brachiaria brizantha cv. Marandu em idades de corte de 28, 35 e 54 dias, respectivamente. Cruz et al. (2010), em avaliação da produção de gases in vitro de cinco variedades de cana-de-açúcar, encontraram valores entre 77,9 a $86,9 \mathrm{~mL}$ para o volume de gases da fraçãos dos CNF, sendo semelhante a média obtida neste trabalho que foi de $86,73 \mathrm{~mL}$.

Tabela 2. Parâmetros da produção de gases in vitro de silagem de Brachiaria decumbens com diferentes doses do aditivo Silogen ${ }^{\circledR}$ pasto.

\begin{tabular}{|c|c|c|c|c|c|c|c|}
\hline & \multicolumn{5}{|c|}{ Teores de aditivo nitrogenado Silogen ${ }^{\circledR}$ pasto ( $\%$ da MN) } & \multirow[t]{2}{*}{$\mathrm{P}$} & \multirow[t]{2}{*}{$\mathrm{CV}$} \\
\hline & 0,0 & 1,0 & 1,5 & 2,0 & 2,5 & & \\
\hline VCNF & 84,03 & 84,68 & 85,05 & 89,12 & 90,81 & 0,057 & 8,72 \\
\hline Kdenf & $0,0313 \mathrm{c}$ & $0,0440 \mathrm{~b}$ & $0,0580 \mathrm{a}$ & 0,0647 a & 0,0653 a & 0,001 & 20,54 \\
\hline $\mathrm{L}$ & $1,61 \mathrm{c}$ & $3,59 \mathrm{~b}$ & $5,98 \mathrm{a}$ & $6,30 \mathrm{a}$ & $6,53 \mathrm{a}$ & 0,001 & 18,72 \\
\hline VCF & $114,74 \mathrm{a}$ & $115,09 \mathrm{a}$ & $109,34 \mathrm{ab}$ & $104,52 \mathrm{~b}$ & $106,71 \mathrm{~b}$ & 0,001 & 5,32 \\
\hline Kdef & $0,0100 \mathrm{c}$ & $0,0120 \mathrm{bc}$ & $0,0153 \mathrm{~b}$ & $0,0193 \mathrm{a}$ & $0,0193 \mathrm{a}$ & 0,001 & 22,24 \\
\hline Vfinal & 197,69 & 199,25 & 191,1 & 195,2 & 195,73 & 0,307 & 3,64 \\
\hline
\end{tabular}

Médias seguidas por letras iguais na mesma linha não diferem pelo teste de Tukey a 5\%. MN: Matéria Natural; VCNF: Volume de gases dos carboidratos não fibrosos (mL); Kdenf: Taxa de degradação dos carboidratos não fibrosos (\%/h); L: Tempo de colonização (lag time) (h); VCF: Volume de gases dos carboidratos fibrosos (mL); kdcf: Taxa de degradação dos carboidratos fibrosos (\%/h); Vfinal: Volume final dos gases produzidos $(\mathrm{mL})$; CV: Coeficiente de Variação. Composição Silogen ${ }^{\circledR}$ pasto: nitrogênio (mínimo) de $360 \mathrm{~g} / \mathrm{kg}$; Bacillus subtilis de $1,25 \times 10^{8} \mathrm{ufc} / \mathrm{kg}$; Lactobacillus curvatus de $1,25 \times 10^{8} \mathrm{ufc} / \mathrm{kg}$; Lactobacillus plantarum de 3,75 x $10^{8} \mathrm{ufc} / \mathrm{kg}$; Pedicoccus acidilactici de $6,25 \times 10^{8} \mathrm{ufc} / \mathrm{kg}$.

Fonte: Elaboração dos autores.

Houve influência dos diferentes teores de aditivos nitrogenados sobre a taxa de degradação dos carboidratos não fibrosos ( $\mathrm{P}<0,05$, Tabela 2$)$. Os teores de aditivo nitrogenados contendo 1,5, 2,0 e
2,5\% apresentaram as maiores taxas de degradação de CNF sendo de 0,$0580 ; 0,0647$ e $0,0653 \% / h$, respectivamente, não diferindo entre si. Observouse que nos teores mais elevados de aditivos 
nitrogenados, aumentou-se a taxa de degradação dos carboidratos não fibrosos, isso provavelmente, ocorreu devido ao menor teor de FDN (Tabela 1) e maiores teores de CNF e fração A+B1 (Tabela 1) para a silagem contendo $2,5 \%$ de aditivo resultando na maior taxa de degradação dos CNF. Cabral et al (2000) avaliando a taxa de degradação de carboidratos não fibrosos pela técnica de produção de gases in vitro, observaram valores de 0,0652 $(\% / \mathrm{h})$ para capim elefante com 42 dias e 0,2225 $(\% / \mathrm{h})$ para capim tifton cortado com $30 \mathrm{~cm}$. Já Sá et al. (2011) e Velásquez et al. (2009) encontraram valores de 0,05 e $0,03(\% / \mathrm{h})$, respectivamente, para a taxa de degradação dos carboidratos não fibrosos (fração de rápida digestão) para o capim Brachiaria brizantha cv. Marandu em diferentes idades de corte, sendo o valor de $0,03(\% / \mathrm{h})$, semelhante ao encontrado neste trabalho para a silagem controle que foi de $0,0313 \% / \mathrm{h}$.

Os teores de aditivos nitrogenados influenciaram ( $\mathrm{P}<0,05$; Tabela 2) o tempo de colonização (L). Observou-se que o tempo de colonização foi maior para os teores de 1,5, 2,0 e 2,5\% de aditivo $(\mathrm{P}<0,05$, Tabela 2). Porém, esperava-se que ocorresse o inverso, que o aumento dos teores de aditivos nitrogenados diminuísse o tempo de colonização (L), pois o nitrogênio é requerido pelos microrganismos ruminais, principalmente os celulolíticos (VAN SOEST, 1994). Porém, podem ter ocorrido fermentações indesejáveis nessas silagens, pois o aumento dos níveis do aditivo nitrogenado, aumentou os teores da capacidade tampão, consequentemente, aumentou o $\mathrm{pH}$ (Tabela 1), pois a uréia utilizada como aditivo, quando quebrada à amônia libera nitrogênio na silagem, que dificulta o abaixamento do $\mathrm{pH}$ (BUMBIERIS JUNIOR et al., 2007), o qual influenciou no tamponamento do meio, impedindo a estabilização do processo fermentativo dessas silagens.

Foi observado que o aumento dos teores de aditivo nitrogenado, aumentou a taxa de colonização (L) (Tabela 2), consequentemente, diminuindo o volume de gases produzidos pelos carboidratos fibrosos. Os teores de aditivo nitrogenado Silogen ${ }^{\circledR}$ pasto também influenciaram o volume de gases produzido pelos carboidratos fibrosos (VCF) ( $\mathrm{P}<0,05$; Tabela 2). As silagens controle $(0,0)$ e $1,0 \%$ de aditivo nitrogenado apresentaram os maiores valores $(\mathrm{P}<0,05)$ de 114,74 e $115,09 \mathrm{~mL}$, respectivamente. Isso se deve aos maiores teores da fração B2 (40,1\%; controle e 41,4\%; 1,0\% aditivo) e redução da fração $\mathrm{C}$ (Tabela 1) nessas silagens, que forneceram substrato (celulose e hemicelulose) para os microrganismos ruminais, e assim promoveram uma maior fermentação e consequentemente o aumento na produção do volume de gases dos carboidratos fibrosos.

Já as silagens com 2,0 e 2,5\% de aditivo nitrogenado apresentaram os volumes de carboidratos fibrosos mais baixos $(\mathrm{P}<0,05)$, possivelmente, por causa dos altos valores de lignina e fração C (Tabela 1) encontrada nessas duas silagens, que como consequência reduzem a disponibilidade dos carboidratos fibrosos e diminui o volume de gases produzido pelos mesmos. Sá et al. (2011) encontraram valores para o volume de gases produzidos pela fração dos carboidatos fibrosos de 83,25; 68,25 e 92,25 mL para Brachiaria brizantha cv. Marandu em idades de corte de 28, 35 e 54 dias, respectivamente. Já Cruz et al. (2010) avaliando o fracionamento e cinética in vitro dos carboidratos de cinco variedades de cana-de-açúcar, observaram valores entre 117,0 e $147,1 \mathrm{~mL}$ de VCF.

Houve influencia dos diferentes teores de aditivo nitrogenado Silogen ${ }^{\circledR}$ pasto sobre a taxa de degradação dos carboidratos fibrosos (kdcf). Observou-se que os níveis de 2,0 e 2,5\% aditivo nitrogenado apresentaram maiores taxas de degradação dos carboidratos fibrosos $(0,0193 \% / \mathrm{h})$, seguidos pelas silagens com 1,0 e 1,5\% de uréia, sendo que a silagem com 1,0\% não diferiu da silagem controle (Tabela 2). Cabral et al (2000) encontraram taxa de degradação dos carboidratos fibrosos de $0,0400(\% / \mathrm{h})$ e $0,0393(\% / \mathrm{h})$ para capim elefante com 42 dias e capim tifton cortado com 30 cm, respectivamente. Sá et al. (2011) encontraram 
valores de $0,01(\% / \mathrm{h})$ para as taxa de degradação dos carboidratos fibrosos (fração de lenta digestão) para o capim Brachiaria brizantha cv. Marandu em diferentes idades de corte.

Não houve influência dos aditivos nitrogenado sobre o volume final de gases produzido $(\mathrm{P}>0,05$; Tabela 2), com a média para os teores de aditivo nitrogenado de 195,79 mL. Observou-se que numericamente o maior valor de volume final de gases produzido foi da silagem contendo $1,0 \%$ de aditivo nitrogenado (199,25 mL). Sá et al. (2011) ao avaliarem a cinética da fermentação in vitro do capim-Marandu em diferentes idades de corte, observaram valores de volume total de gases produzidos de 179,185 e $160 \mathrm{~mL}$ para as idades de corte de 28, 35 e 54, respectivamente. Já Castro et al. (2007) ao avaliarem a cinética de degradação da Brachiaria brizantha cv. Marandu colhida em diferentes idades ao corte, encontraram valores entre 233,1 a 241,3 $\mathrm{mL}$ para o volume de gases produzidos, ao tempo de 96 horas de incubação para o capim-marandu com idades entre 28 a 112 dias.

\section{Conclusão}

A silagem de Brachiaria decumbens com uso de teores menores de aditivo nitrogenado até $1,5 \%$, promoveu menor fração não degradável (C) e maior fração potencialmente degradável (B2) no fracionamento dos carboidratos, o que contribuiu para a maior produção de volume de gases dos carboidratos fibrosos, demonstrando silagens com melhor valor nutricional. $\mathrm{O}$ aumento dos teores de inclusão do aditivo na silagem promoveu aumento na taxa de degradação dos carboidratos fibrosos e não fibrosos e no tempo de colonização pelos microrganismos.

\section{Agradecimentos}

À empresa BIOCAMPO NUTRIÇÃO ANIMAL pelo fornecimento dos aditivos microbianos para a realização do experimento.
O experimento foi aprovado pelo Comitê de Ética em Experimentação Animal (CEUA/UEL), sob o protocolo $\mathrm{n}^{\mathrm{o}} 17841.2012 .53$.

\section{Referências}

BARBOSA, G. M. C.; TAVARES FILHO, J.; FONSECA, I. C. B. Condutividade hidráulica saturada e não saturada de latossolo vermelho eutroférrico tratado com lodo de esgoto. Revista Brasileira de Ciência do Solo, Viçosa, MG, v. 28, n. 2, p. 403-407, 2004.

BUMBIERIS JUNIOR, V. H.; DIAS, F. J.; KAZAMA, R.; ARRUDA, D. S. R.; JOBIM, C. C.; MORAIS, M. G. Degradabilidade ruminal e fracionamento de carboidratos de silagens de grama estrela (Cynodon nlemfuensis vanderyst.) com diferentes aditivos. Semina: Ciências Agrárias, Londrina, v. 28, n. 4, p. 761-772, out./ dez. 2007.

CABRAL, L. S.; VALADARES FILHO, S. C.; DETMANN, E.; ZERVOUDAKIS, T.; VELOSO, R. G.; NUNES, P. M. M. taxas de digestão das frações protéicas e de carboidratos para silagem de milho e de capimelefante, o feno de capim-tifton- 85 e o farelo de soja. Revista Brasileira de Zootecnia, Viçosa, MG, v. 33, n. 6, p. 1573-1580, 2004.

CABRAL, L. S.; VALADARES FILHO, S. C.; MALAFAIA, P. A. M.; LANA, R. P. de; SILVA, J. F. C. da; SILVA, J. F. C. da; VIEIRA, R. A. M.; PEREIRA, E. $\mathrm{S}$. Frações de carboidratos de alimentos volumosos e suas taxas de degradação estimadas pela técnica de produção de gases. Revista Brasileira de Zootecnia, Viçosa, MG, v. 29, n. 6, p. 2087-2098, 2000. Suplemento 1.

CAMPOS, F. P.; BOSE, M. L. V.; BOIN, C.; LANNA, D. P. D.; MORAIS, J. P. G. Avaliação do sistema de monitoramento computadorizado de digestão in vitro. Desaparecimento da matéria seca e/ou FDN pela produção de gás. Revista Brasileira de Zootecnia, Viçosa, MG, v. 29, n. 2, p. 537-544, 2000.

CAMPOS, F. P.; LANNA, D. P. D.; BOSE, M. L. V.; BOIN, C.; SARMENTO, P. Degradabilidade do capim-elefante em diferentes em diferentes estágios de maturidade avaliada pelo método in vitro/gás. Scientia Agrícola, Piracicaba, v. 59, n. 2, p. 217-225, abr.jun. 2002.

CASTRO, G. H. F.; GRAÇA, D. S.; GONÇALVES, L.C.; MAURICIO, R. M.; RODRIGUEZ, N. M.; BORGES, I.; TOMICH, T. R. Cinética de degradação e fermentação ruminal da Brachiaria brizantha cv. Marandu colhida em diferentes idades ao corte. Arquivo Brasileiro de Medicina Veterinária e Zootecnia, v. 59, n. 6, p. 15381544, 2007. 
CRUZ, P. G. da; FIGUEIREDO, M. P. de; PEREIRA, L. G. R.; BERGAMASCHI, K. B.; RODRIGUES, C. S. RECH, C. L. S. Fracionamento e cinética da fermentação ruminal in vitro dos carboidratos de cinco variedades de cana-de-açúcar. Ciência Animal Brasileira, Goiânia, v. 11, n. 4, p. 784-793, out./dez. 2010.

DETMANN, E.; SOUZA, M. A.; VALADARES FILHO, $\mathrm{S}$. C. Métodos para análise de alimentos. Visconde do Rio Branco: Universidade Federal de Viçosa, 2012. 214 p.

EVANGELISTA, A. R.; ABREU, J. G.; AMARAL, P. N. C.; PEREIRA, R. C.; SALVADOR, F. M.; SANTANA, R. A. V. Produção de silagem de capim-marandu (Brachiaria brizantha Stapf cv. Marandu) com e sem emurchecimento. Ciência e Agrotecnologia, Lavras, v. 28, n. 2, p. 443-449, mar./abr. 2004.

FERNANDES, F. E. P.; GARCIA, R.; PIRES, A. J. V.; PEREIRA, O. G.; CARVALHO, G. G. P.; OLIVINDO, C. S. Ensilagem de sorgo forrageiro com adição de uréia em dois períodos de armazenamento. Revista Brasileira de Zootecnia, Viçosa, MG, v. 38, n. 11, p. 2111-2115, 2009.

HERNÁNDEZ, F. I. L.; VALADARES FILHO, S. C.; PAUlINO, M. F.; MANCIO, A. B.; CECON, P. R.; LANA, R. P.; MAGALHÃES, K. A.; REIS, S. L. R. Avaliação da composição de vários alimentos e determinação da cinética ruminal da proteína, utilizando o método de produção de gás e amônia in vitro. Revista Brasileira de Zootecnia, Viçosa, MG, v. 31, n. 1, p. 243255, 2002.

JAYME, C. G.; MOLINA, L. R.; GONÇALVES, L. C.; JAYME, D. G.; PIRES, D. A. A.; BORGES, I. Determinação do momento de colheita da Brachiaria brizantha (Hochest.) Stapf. Cv. Marandu para produção de silagem. Ciência e Agrotecnologia, Lavras, v. 33, n. 2 , p. 586-591, mar./abr. 2009.

MALAFAIA, P. A. M.; VALADARES FILHO, S. C. de; VIEIRA, R. A. M.; SILVA, J. F. C. da; PEREIRA, J. C. Determinação das frações que constituem os carboidratos totais e da cinética ruminal da fibra em detergente neutro de alguns alimentos para ruminantes. Revista Brasileira de Zootecnia, Viçosa, MG, v. 27, n. 4, p. 790-796,1998.

MARI, L. J. Intervalo entre cortes em capim-marandu (Brachiaria brizantha (Hochst. Ex A. Rich.) Stapf. cv. Marandu): produção, valor nutritivo e perdas associadas à fermentação da silagem. 2003. Dissertação (Mestrado em Agronomia) - Escola Superior de Agricultura Luiz de Queiroz, Piracicaba.

MAURÍCIO, R. M.; PEREIRA, L. G. R.; GONÇALVES, L. C.; RODRIGUEZ, N. M.; MARTINS, R. G. R.; RODRIGUES, J. A. S. Potencial da técnica in vitro semi-automática de produção de gases para avaliação de silagens de sorgo (Sorghum bicolor (L.) Moench). Revista Brasileira de Zootecnia, Viçosa, MG, v. 32, n. 4, p. 1013-1020, 2003.

McDOUGAL, E. I. Studies on ruminant saliva. 1. The composition and output of sheep's saliva. Biochemical Journal, London, v. 43, n. 1, p. 99-109, 1949.

MIZUBUTI, I. Y.; PINTO, A. P.; RAMOS, B. M. O.; PEREIRA, E. S. Métodos laboratoriais de avaliação de alimentos para animais. Londrina: EDUEL, 2009. 228 p.

MORAIS, M. G.; ÍTAVO, C. C. B. F.; ÍTAVO, L. C. V.; BUNGENSTAB, D. J.; RIBEIRO, C. B.; OLIVEIRA, L. B.; SILVA, J. A. Inoculação de silagens de grãos úmidos de milho, em diferentes processamentos. Revista Brasileira de Saúde e Produção Animal, Salvador, v. 13, n. 4, p. 969-981, out./dez. 2012.

PIMENTEL, J. J. O.; SILVA, J. F. C.; VALADARES FILHO, S. C.; CECON, P. R.; SANTOS, P. S. Efeito da suplementação protéica no valor nutritivo de silagens de milho e sorgo. Revista Brasileira de Zootecnia, Viçosa, MG, v. 27, n. 5, p. 1042-1049, 1998.

PLAYNE, M. J.; McDONALD, P. The buffering constituents of herbage and silage. Journal of Science Food and Agriculture, London, v. 17, n. 2, p. 262-268, 1966.

R DEVELOPMENT CORE TEAM. $R$ : a language and environment for statistical computing. R Foundation for Statistical Computing: Vienna, Austria, 2013. Disponível em: <http://www.R-project.org >. Acesso em: 04 nov. 2013.

SÁ, J. F. de; PEDREIRA, M. S.; SILVA, F. F. da; FIGUEIREDO, M. P. de; REBOUÇAS, G. M. N.; SOUZA, D. R. de. Cinética da fermentação in vitro do capim-marandu em diferentes idades de corte. Acta Scientiarum Animal Sciencens, Maringá, v. 33, n. 3, p. 225-231, 2011.

SANTOS, E. M.; ZANINE, A. M. Silagens de gramíneas tropicais. Colloquium Agrariae, Presidente Prudente, v. 2, n. 1, p. 32-45, mar. 2006.

SCHOFIELD, P.; PITT, R. E.; PELL, A. N. Kinetic of fiber digestion from in vitro gas production. Journal of Animal Science, v. 72, n. 11, p. 2980-2991, 1994.

SILVA, D. J.; QUEIROZ, A. C. Análise de alimentos: métodos químicos e biológicos. Viçosa: UFV, 2002. 235 p.

SNIFFEN, C. J.; O'CONNOR, J. D.; VAN SOEST, P. J.; FOX, D. G.; RUSSELL, J. B. A net carbohydrate and protein system for evaluating cattle diets: II. Carbohydrate and protein availability. Journal of Animal Science, Madison, v. 70, n. 12, p. 3562-3577, 1992. 
VAN SOEST, P. J. Nutritional ecology of the ruminant. 2. ed. Ithaca: Cornell University Press, 1994. 476 p.

VAN SOEST, P. J.; ROBERTSON, J. B.; LEWIS, B. A. Symposium: carbohydrate methodology, metabolism and nutritional implications in dairy cattle. Journal of Dairy Science, Madison, v. 74, n. 10, p. 3583-3597, 1991.

VELÁSQUEZ, P. A. T.; BERCHIELLI, T. T.; REIS, R. A.; RIVERA, A. R.; DIAN, P. H. M.; TEIXEIRA, I. A. M. de. Cinética da fermentação e taxas de degradação de forrageiras tropicais em diferentes idades de corte estimadas pela técnica de produção de gases in vitro. Revista Brasileira de Zootecnia, Viçosa, MG, v. 38, n. 9, p. 1695-1705, 2009.

VELÁSQUEZ, P. A. T.; BERCHIELLI, T. T.; REIS, R. A.; RIVERA, A. R.; DIAN, P. H. M.; TEIXEIRA, I. A. M. de A. Composição química, fracionamento de carboidratos e proteínas e digestibilidade in vitro de forrageiras tropicais em diferentes idades de corte. Revista Brasileira de Zootecnia, Viçosa, MG, v. 39, n. 6, p. 1206-1213, 2010. 
